\title{
Possibilidades e limites da teoria documentária aplicada a Nm 14,1-38
}

\author{
Possibilities and limitations of documentary theory \\ applied to Num. 14, 1-38
}

Fabrizio Zandonadi Catenassi

\section{Resumo}

Nesta comunicação, busca-se investigar se a teoria documentária de fato conseguiu responder às questões das diferentes fontes que deram origem a $\mathrm{Nm}$ 14,1-38 ou se os resultados ainda apresentam fortes graus de inconsistência. Para isso, são apresentadas análises de autores de diferentes períodos para acompanhar o desenvolvimento histórico da pesquisa exegética da perícope em questão. Após uma análise das primeiras pesquisas da hipótese crítica, são indicados os resultados dos principais estudos sobre Números ao longo do último século, com especial ênfase a G. B. Gray e M. Noth. Foram apontadas as principais incidências da crise da teoria documentária do Pentateuco em $\mathrm{Nm}$ 14,1-38. Por fim, diante dos resultados das pesquisas exegéticas, foram ressaltadas as contradições encontradas. Pode-se concluir que há um consenso geral nos estudos histórico-críticos da perícope, que podem ser aceitos não com poucas dúvidas e que as limitações que apresentam indicam a necessidade de métodos sincrônicos de análise.

Palavras-chave: Teoria documentária; Números; Diacronia; Sincronia.

\section{Abstract}

In this communication, we aim to investigate if the Documentary Hypothesis has achieved answers about the different fonts that originated 
Num 14,1-38 or if the results have strong levels of inconsistency yet. For this, there were presented analysis from different authors and periods to get a historical view of the exegetical research of the perícope studied. After an analysis of the first studies of the critical hypothesis applied to Numbers, we indicate the main results of them, with special emphasis to G. B. Gray and M. Noth. It were highlighted the main incidences of the documentary theory's crisis of Pentatheuc on Num 14,1-38. Finally, considering the results of the exegetical researches, we have emphasized the contradictions found on them. We can conclude that there is a consensus in the historical-critical studies of the perícope, which can be accepted with many doubt and that the limitations presented indicate the necessity of methods of synchronic analysis.

Keywords: Documents Hypothesis; Numbers; Diachrony; Synchrony.

\section{Introdução}

Em 1966, ao escrever seu comentário sobre Números, Martin Noth indicava que a aplicação da teoria das fontes a este livro deveria ser feita com cautela e restrição. $\mathrm{O}$ autor não reconhecia elementos de unidade entre os variados materiais que tinham sido agrupados e justapostos, indicando um confuso processo de redação final ${ }^{1}$. De fato, os estudiosos de criticismo usualmente encontraram bastante dificuldade na análise das fontes dos caps. 13-14, desde tempos remotos. Há claras repetições, especialmente em Nm 14,1-38, que, ao longo do tempo, foram atribuídas a diferentes redatores e períodos redacionais. Diante da aparente disparidade entre os exegetas, a questão é se a teoria documentária de fato conseguiu responder às questões das diferentes fontes que deram origem à perícope em questão em sua forma final ou se os resultados ainda são inconsistentes demais, indicando a necessidade da análise sincrônica. Para isso, são apresentadas análises de autores de diferentes períodos, não de maneira exaustiva, para que o leitor acompanhe o desenvolvimento histórico da pesquisa exegética da perícope em questão. A partir deste estudo inicial, procura-se também ao menos uma visão provisória sobre até que ponto a diacronia e a sincronia podem dialogar na busca de chegar, de fato, a acessar a intencionalidade do autor impressa nas narrativas de Números, assim como já foi apontado no estudo dos caps. 16-17 por V. Artuso ${ }^{2}$.

\footnotetext{
${ }^{1}$ NOTH, M. Numbers: a commentary. London: SCM Press, 1968, p. 4-5.

${ }^{2}$ ARTUSO, V. A teoria documentária do Pentateuco: aplicação e limites na análise de Nm 16-17. Atualidade Teológica 16 (2012) 279-300.
} 


\section{Os primeiros estudos da hipótese crítica aplicada a Nm 14,1-38}

Os comentários do livro de Números da segunda metade do séc. XIX são representativos da disputa entre a interpretação clássica que assumia a autoria mosaica e os estudos de criticismo que começavam a tomar o meio acadêmico. J. Lange tenta, com grande veemência, minar as conclusões dos estudos de criticismo em textos bíblicos da época, defendendo que Números é um tipo de "diário de viagem de Moisés, sendo que o aparente duplo discurso de Deus que está em Nm 14,11-25 e 14,26-35 são entendidos por Lange e G. Bush como uma simples repetição da fala divina ${ }^{3}$.

Em 1866, A. Kuenen publica uma análise crítica dos livros do Antigo Testamento, indicando que Nm 14,26-35 é supérfluo depois dos vv. 11-25, sendo uma repetição de fonte diferente. O primeiro discurso de Deus seria obra de J, usando documentos antigos que também deram base a Ex 32-34 e o outro seria do Livro das origens. Também constata que em Nm 14,6.30.38 Josué aparece com Caleb diante do povo, o que destoa do início da narrativa em 13,304. T. Nöldeke também atribui os vv. 1-10 e 26-38 à fonte-base (P), ainda que indique acréscimos posteriores ${ }^{5}$. Assim, está planteada a questão das duas fontes que deram origem à passagem: $\mathrm{P}$ e $\mathrm{J}$.

Driver $(1891)^{6}$ já demonstra que há uma narrativa intercalada entre $\mathrm{P}$ e JE, mas admite que o início de JE foi omitido, sendo a introdução da narrativa exclusivamente de P. Em 1893, P. Nordell publicou um artigo na The Biblical World, de Chicago, sendo contestado dois meses depois por H. Green ${ }^{7}$. Nordell reconstrói o relato de $\mathrm{P}$ e JE que teriam sido agregados nestes capítulos, querendo demonstrar que Nm 13-14 são uma prova da autoria não-mosaica do Pentateuco. A resposta de Green, em oposição, peca em sua premissa: uma aparência de unidade não pode existir a não ser que a unidade seja real. Como os capítulos tem uma unidade narrativa, seriam escritos por um mesmo autor.

\footnotetext{
${ }^{3}$ BUSH, G. Notes, critical and practical on the Book of Numbers. New York: Ivison \& Phinney, 1858, p. iii; LANGE, J. P. Numbers. Grand Rapids: Zondervan, 1866, p. 1-9.

${ }^{4}$ KUENEN, A. Histoire critique des livres de L'Ancien Testament. Paris: Michel Lévy Frères, 1866, p. 162.

${ }^{5}$ NÖLDEKE, T. Untersuchungen zur Kritik des Alten Testaments. Kiel: Schwer'sche, 1869, p. 143-144.

${ }^{6}$ DRIVER, S. R. An introduction to the literature of the Old Testament. New York: Charles Scribner's sons, 1891, p. 60.

${ }^{7}$ NORDELL, P. A. The story of the spies: a study in biblical criticism. The Biblical World 1 (1893) 168-183; GREEN, H. "The story of the spies" once more. The Biblical World 1 (1893) 328-344.
} 
Green desconsidera a possibilidade de um compilador com grande habilidade literária ter unido as duas diferentes tradições. Contudo, faz apontamentos bastante interessantes com relação à hipótese crítica, especialmente dizendo que a separação do texto a partir da atribuição a diversas fontes não favorece a compreensão seus elementos primários em vista da unidade do texto, e sim a contemplação de fragmentos separados, sem a visão do todo.

\section{O desenvolvimento das investigações}

Um dos comentários mais clássicos de Números é o de George Buchanan Gray, de 1903, considerando elementos estilísticos, temáticos e linguísticos. Reconhecendo as numerosas incongruências nos detalhes de Nm 13-14, algumas irreconciliáveis, o autor busca reconstruir a história da tradição, entendo que a primeira versão do discurso de Deus e argumentação de Moisés (vv.11-24) não fazia parte de J ou E, mas foi assimilada em JE. Também indica uma provável remodelação da versão sacerdotal do discurso divino, especialmente nos vv. 29-33. Gray indicou algumas possibilidades que não podiam ser comprovadas a partir da teoria das fontes, assim como era compreendida no momento: (a) os vv. 3.8.9a podem ser de $\mathrm{P}$; (b) pode haver influência de $\mathrm{E}$, como no v. 26; (c) os vv. 31-33 podem ser JE ou J e talvez o 28 também seja de $\mathrm{J}^{8}$.

Os comentadores imediatamente subsequentes de Números não apresentaram grandes avanços. Kennedy, por exemplo, diferente de Gray, somente atribui com precisão os vv. 31-32 a JE; McNeile atribui os vv. 1. 31 a JE9 . Contudo, pouco se diferenciam do já proposto por Gray. Martin Noth traz novas contribuições. Em seu comentário de $1966^{10}$, indica que há uma evidente justaposição de duas narrativas, mas não no plano das "velhas fontes", além de contar com inserções deuteronomistas. Traços deuteronomistas já haviam sido sinalizados por J. Colenso no final do séc. $\mathrm{XIX}^{11}$; contudo, autores como

\footnotetext{
${ }^{8}$ GRAY, G. B. A critical and exegetical commentary on Numbers. Edinburgh: T \& T Clark, 1976, p. 129.

9 KENNEDY. A. R. S. Leviticus and Numbers: introduction, revised version with notes, index and maps. New York: Harder, 1910[?], p. 18; MCNEILE, A. H. The Book of Numbers. Cambridge: Cambridge University, 1911, p. 72-77.

${ }^{10}$ Sigo a tradução em inglês, de 1968: NOTH, Numbers, p. 109-111.

${ }^{11}$ Em 1865, este bispo sul-africano fez uma tradução para o inglês de um material de Kuenen, The Pentateuch and Book of Joshua critically examined (London: Longman, 1865, p. 124), ampliando significativamente a obra original com notas críticas, indicando provável presença deuteronomista em 14,7.11-25.
} 
E. Flack não remontam nenhuma parte de Nm 14,1-38 a $\mathrm{D}^{12}$. Para Noth, o relato de $\mathrm{P}$ seria a base que se manteve intacta, unida com $\mathrm{J}$, narrativa mais antiga, que perdeu alguns elementos nesta fusão. A narrativa teria suas raízes na conquista de Hebron e seus arredores pelos "Calebitas" (Js 15,13-14), que teriam aceitado o Deus de Israel, por isso, puderam entrar na terra ${ }^{13}$. Depois, $\mathrm{J}$ teria colocado todo o povo de Israel no relato, da mesma forma que $\mathrm{P}$ o fez, explicando o porquê da peregrinação no deserto.

Em 1968, G. Coats, que estudou extensivamente as tradições de rebelião no deserto, trabalha de maneira bastante conciliadora com as fontes de $\mathrm{Nm}$ $13-14^{14}$. O autor diz que a análise das fontes dessa seção não apresenta grandes dificuldades. No geral, indica a fusão de uma narrativa J e uma P, atribuindo aos versículos a mesma classificação de Noth, diferenciando-se nos v. 26-38, os quais considera uma seção única de $\mathrm{P}$, considerando uma composição com maiores complexidades nos vv. 11-25. Indica que o 25a é uma adição a J e diz que 25 b é uma afirmação conclusiva, mas não determina de maneira clara de qual fonte provém. $\mathrm{O}$ autor vê uma coleção de vários materiais que foram adicionados à fonte $\mathrm{J}$ mas não consegue identificar com precisão sua origem. Em seguida, a revista Biblica, do Pontifício Instituto Bíblico, publicou um artigo de S. McEvenue em $1969^{15}$, discutindo a grande dificuldade de analisar a história dos espiões de Nm 13-14, especialmente a seção de 14,26-38. Com bastante dificuldade, o autor busca compreender a natureza dos vv. 28-29 e do v. 34, indicando a grande disparidade das análises ao longo do tempo, que já haviam atribuído estes versículos à redação de $\mathrm{P}^{\mathrm{g}}, \mathrm{P}^{\mathrm{s}}, \mathrm{J}, \mathrm{JE}$, ao redator final do Pentateuco e a um acréscimo último em forma de glosa.

A partir dos estudos conduzidos após a "era heroica", fica claro que a crítica das fontes havia produzido resultados suficientemente díspares com relação a Nm 14,1-38, algumas vezes contraditórios e que alguns versículos, como o 34, estavam longe de serem atribuídos a determinada fonte de maneira mais consensual. Entretanto, traços gerais da composição podiam ser identificados com mais segurança. A situação começa a ganhar novas nuances com a crise na teoria documentária.

\footnotetext{
${ }^{12}$ FLACK, E. E. Flashes of New Knowledge. Interpretation 13 (1959) 3-23.

${ }^{13} \mathrm{Em}$ 1878, J. Wellhausen (Prolegomena to the history of Israel, Edinburgh: C. \& A. Clark, 1885) já havia indicado que Josué e Caleb provavelmente não estavam na narrativa original; Caleb foi facilmente inserido porque havia conquistado o distrito de Cades a Hebron, que os espiões haviam declarado impossível de tomar.

${ }^{14}$ COATS, G. W. Rebellion in the wilderness. Nashville: Abingdon, 1968, p. 137-156.

${ }^{15}$ MCEVENUE, S. A source-critical problem in Nm 14,26-38. Biblica 50 (1969) 453-465.
} 


\section{A influência da crise na teoria documentária nos estudos de Números}

Em 1970, J. A. Thompson escreve uma introdução ao livro de Números para o The New Bible Commentary: Revised, buscando abranger as mais recentes descobertas no campo bíblico. Em uma introdução às fontes de Números, indica que cem anos de pesquisa documentária clássica produziram um panorama das fontes esmerado, mas distorcido e que a divisão estrita em material antigo em forma de epopeia (JE) unido a uma reinterpretação mais cúltico e legalista $(\mathrm{P})$ seria em grandes partes artificial se não considerasse com um maior grau de flexibilidade a atribuição de versículos às fontes.

De fato, a teoria documentária clássica passou por uma grande crise, especialmente a partir da década de 70 . Muitas questões foram discutidas ${ }^{16}$, sendo que, atualmente, a fonte Javista é pouco aceita ou não se sabe de quando datá-la e há os que postulam bani-la, como E. Blum. O modelo de P. Weimar e E. Zenger, da escola de Münster, trouxe resultados bastante inovadores, indicando uma datação muito mais tardia para o material Javista. A fonte Eloísta há muito tempo tem sido negada por vários estudiosos, como A. Campbell e $\mathrm{M}$. O'Brien, pela falta de elementos em comum que unifiquem o material arremetido a ela e justifiquem sua existência. A sacerdotal, que sempre pareceu mais identificável, recebe grandes críticas sobre sua natureza, teologia, datação e abrangência, apesar de ser uma das poucas que se mantém. A separação e datação do material deuteronomista são extremamente difíceis e encontram resultados bastante distintos.

Outra problemática recente é a presença de material sacerdotal em P. Otto $^{17}$ cita o estudo de T. Pola, Die ursprüngliche Priesterchrift (1995), o qual não encontra nenhum indício de $\mathrm{P}$ em Números, obrigando a busca do

\footnotetext{
${ }^{16}$ Preferi não apresentar aqui exaustivamente o status quaestionis acerca da pesquisa das fontes do Pentateuco. Boas análises podem ser encontradas em DE PURY, A.; RÖMER, T. O Pentateuco em questão: posição do problema e breve história da pesquisa. In: DE PURY, A. (Org.). O Pentateuco em questão: as origens e composição dos cinco primeiros livros da Bíblia à luz das pesquisas recentes. Petrópolis: Vozes, 1996; SKA, J. L. Introdução à leitura do Pentateuco: chaves para a interpretação dos cinco primeiros livros da Bíblia. São Paulo: Loyola, 2003, p. 145-174; DOZEMAN, T. B; SCHMID, K.; SCHWARTZ, B. J. (Orgs.). The Pentateuch: international perspectives on current research. Tübingen: Mohr Siebeck, 2011. Aplicada ao livro dos Números, cf. ARTUSO, A teoria documentária do Pentateuco, p. 279-300; RÖMER, T. The Books of Leviticus and Numbers. Leuven: Peeters, 2008.
}

${ }^{17}$ OTTO, E. A lei de Moisés. São Paulo: Loyola, 2011. p. 183-184. 
término do escrito sacerdotal na perícope do Sinai. Assim, Otto procura fundamentar sua própria teoria de que o relato sacerdotal tem um fim aberto com a promessa da habitação no meio do povo na tenda do encontro em Ex 29,4246, que chega a seu cumprimento a partir de uma ampliação pós-exílica dos acontecimentos em Lv 9. Se o propósito único de P é a instauração do culto, é possível adiantar o fim de P para Ex 40 ou Lv 9. Entretanto, Ska discute o tema a partir de Gn 17 e Ex 6,2-8 ${ }^{18}$, que apresentam um vocabulário marcadamente sacerdotal. Segundo o autor, as duas passagens fazem uma referência explícita à terra, revelando um dos interesses fundamentais de $\mathrm{P}$, indicando que a preocupação com o culto não é a exclusiva em seus relatos. Também é preciso explicar porque Moisés, Aarão e todo o povo não foram contemplados com a entrada na terra prometida junto com toda a comunidade do êxodo, o que não permite excluir passagens como Nm 13-14; 20,1-13; 20,22-29 e 27 do relato sacerdotal.

Ainda que alguns comentários de Números mantenham a análise a partir da teoria clássica das fontes, como Budd ${ }^{19}$, outros autores já não trazem mais a terminologia J, E, JE e D. O. Artus ${ }^{20}$, por exemplo, afirma que podem ser identificadas algumas tradições narrativas que são mais antigas, de antes do exílio, as quais denomina "tradições antigas", abrindo mão das siglas antigas J, E e JE. Segundo Artus, há um relato sacerdotal de Nm 13-14, que contém detalhes narrativos menos desenvolvidos que o relato antigo, valorizando a relação culpa-castigo e sendo uma ilustração da lei. Junto às tradições antigas, está uma teologia mais tardia que se opõe a sacerdotal, talvez deuteronomista, expressa nos vv. 13-20. P. Buis ${ }^{21}$ também reconhece camadas redacionais antigas costuradas por uma redação sacerdotal, mas abre mão da análise clássica de criticismo diante das incertezas oriundas da teoria documentária. Para ele, só é possível determinar que, antes do sacerdotal, houve uma interpretação pela tribo de Judá referente à conquista da Judéia a partir de Cades liderada por Caleb e outra que põe Moisés em relevo, coincidindo com outros textos da redação profética. A redação sacerdotal analisa mais profundamente a falta do povo, explicitamente, os espiões denegrindo o país dado pelo Senhor.

\footnotetext{
${ }^{18}$ SKA, Introdução à leitura do Pentateuco, p. 161-163.

${ }^{19}$ BUDD, P. J. Numbers. Texas: General Editors, 1984.

${ }^{20}$ ARTUS, O. Aproximación actual al Pentateuco. 2. ed. Navarra: Verbo Divino, 2003, p. 33.

${ }^{21}$ BUIS, P. El libro de los Números. 4. ed. Estella: Verbo Divino, 2005. O original em francês é de 1992.
} 


\section{Análise das seções de $\mathrm{Nm}$ 14,1-38: resultados contraditórios}

Para visualizar de maneira mais plástica as diferentes propostas de análise das seções de Nm 14,1-38 por autores de períodos distintos ${ }^{22}$, foram elaborados quadros comparativos, nos quais cada linha representa a classificação dada por um autor aos versículos, que são, por sua vez, indicados nas colunas. Quando determinado autor não indicou a fonte de alguma seção, as células são preenchidas por asteriscos. Pela natureza breve desta comunicação, somente alguns versículos serão analisados pormenorizadamente.

Quadro 1 - Fontes dos vv. 1-4 (murmuração e revolta) e 5-9 (intervenção de Caleb e Josué).

\begin{tabular}{|c|c|c|c|c|c|c|c|c|c|c|c|}
\hline & \multicolumn{3}{|c|}{1} & \multirow{2}{*}{2} & \multirow{2}{*}{3} & \multirow{2}{*}{4} & \multirow{2}{*}{5} & \multirow{2}{*}{6} & \multirow{2}{*}{7} & \multirow{2}{*}{8} & \multirow{2}{*}{9} \\
\hline & $\mathrm{a}$ & $\mathrm{b}$ & $\mathrm{c}$ & & & & & & & & \\
\hline Gray (1903) & $\mathrm{P}$ & $\mathrm{JE}$ & $\mathrm{J} / \mathrm{P}$ & $P$ & \multicolumn{2}{|c|}{ JE } & \multicolumn{3}{|c|}{$\mathrm{P}$} & \multicolumn{2}{|c|}{ JE } \\
\hline Noth (1966) & $\mathrm{P}$ & $\mathrm{J}$ & \multicolumn{3}{|c|}{$\mathrm{P}$} & $\mathrm{P} / \mathrm{J}$ & \multicolumn{5}{|c|}{ P (9a adição posterior) } \\
\hline Coats (1968) & \multicolumn{2}{|c|}{$\mathrm{P}$} & $\mathrm{J}$ & \multicolumn{2}{|c|}{$\mathrm{P}$} & $\mathrm{P} / \mathrm{J}$ & \multicolumn{5}{|c|}{$\mathrm{P}$} \\
\hline Budd (1984) & $\mathrm{P}$ & \multicolumn{2}{|c|}{$\mathrm{J}$} & \multicolumn{2}{|c|}{$\mathrm{P}$} & $\mathrm{J}[?]$ & \multicolumn{3}{|c|}{$P$} & \multicolumn{2}{|c|}{$\mathrm{J}$} \\
\hline Artus (2001) & $\mathrm{P}$ & \multicolumn{2}{|c|}{ relato antigo } & \multicolumn{2}{|c|}{$\mathrm{P}$} & r. antigo & $P$ & \multicolumn{4}{|c|}{$* * * * * * * * * * * * *$} \\
\hline
\end{tabular}

Quadro 2 - Fontes dos vv. 10-12 (aparição da glória de YHWH e condenação do povo) e dos vv. 13-19 (intercessão de Moisés).

\begin{tabular}{|c|c|c|c|c|c|c|c|c|c|c|c|}
\hline & 10 & $\mathrm{a}$ & $b$ & 12 & 13 & 14 & 15 & 16 & 17 & 18 & 19 \\
\hline Gray (1903) & $\mathrm{P}$ & \multicolumn{10}{|c|}{$\mathrm{J}$} \\
\hline Noth (1966) & $\mathrm{P}$ & $\mathrm{J}$ & \multicolumn{9}{|c|}{$\mathrm{J}$, mas com uma importante inserção posterior de D } \\
\hline Coats (1968) & $\mathrm{P}$ & $\mathrm{J}$ & \multicolumn{9}{|c|}{ J com inserção de coleção de materiais } \\
\hline Budd (1984) & $P$ & $\mathrm{~J}$ & \multicolumn{9}{|c|}{ Expansão exílica de J, com inserção de D e outras influências } \\
\hline Artus (2003) & $\mathrm{P}$ & $\begin{array}{l}\text { relato } \\
\text { antigo }\end{array}$ & \multicolumn{2}{|c|}{$\begin{array}{l}\text { releitura } \\
\text { tardia de } \mathrm{P}\end{array}$} & \multicolumn{7}{|c|}{$\begin{array}{l}\text { Inserção deuteronomista } \\
\text { ou pós-deuteronomista }\end{array}$} \\
\hline
\end{tabular}

\footnotetext{
${ }^{22}$ Após o nome do autor, segue o ano original de sua publicação, ainda que a obra consultada seja uma tradução posterior. Os autores referidos são: GRAY, A critical and exegetical commentary on Numbers; NOTH, Number; COATS, Rebellion in the wilderness; BUDD, Numbers; ARTUS, Aproximación actual al Pentateuco; MCEVENUE; A source-critical problem in Nm 14,26-38; MCNEILE, The Book of Numbers.
} 
Quadro 3 - Fontes dos vv. 20-25 (proclamação do juízo sobre o povo).

\begin{tabular}{|c|c|c|c|c|c|c|c|c|}
\hline & \multirow{2}{*}{20} & \multirow{2}{*}{21} & \multirow{2}{*}{22} & \multicolumn{2}{|c|}{23} & \multirow{2}{*}{24} & \multicolumn{2}{|c|}{25} \\
\hline & & & & $\mathrm{a}$ & $\mathrm{b}$ & & $\mathrm{a}$ & $\mathrm{b}$ \\
\hline Gray (1903) & \multicolumn{8}{|c|}{$\mathrm{J}$} \\
\hline Noth (1966) & \multicolumn{4}{|c|}{$\begin{array}{l}\mathrm{J} \text {, mas com uma importante inserção } \\
\text { posterior deuteronomista. }\end{array}$} & & $\mathrm{J}$ & $\begin{array}{l}\text { verso } \\
\text { desloc. }\end{array}$ & $\mathrm{J}$ \\
\hline Coats (1968) & \multicolumn{4}{|c|}{$\mathrm{J}$ com inserção de coleção de materiais } & & $\mathrm{J}$ & $\mathrm{J}$ adic. & $* * * *$ \\
\hline Budd (1984) & \multicolumn{4}{|c|}{$\begin{array}{l}\text { Expansão exílica de J, com inserção de D } \\
\text { e outras influências. }\end{array}$} & \multicolumn{4}{|c|}{$\mathrm{J}$} \\
\hline Artus (2001) & $\begin{aligned} & \text { igual a } \\
& \text { v. } 19\end{aligned}$ & \multicolumn{3}{|c|}{ releitura tardia de $\mathrm{P}$} & \multicolumn{4}{|c|}{ relato antigo (a partir do $23 \mathrm{~b})^{23}$} \\
\hline
\end{tabular}

Quadro 4 - Fontes dos vv. 26-35 (proclamação do juízo sobre o povo - cont.) e 36-38 (castigo dos espiões). ${ }^{23}$

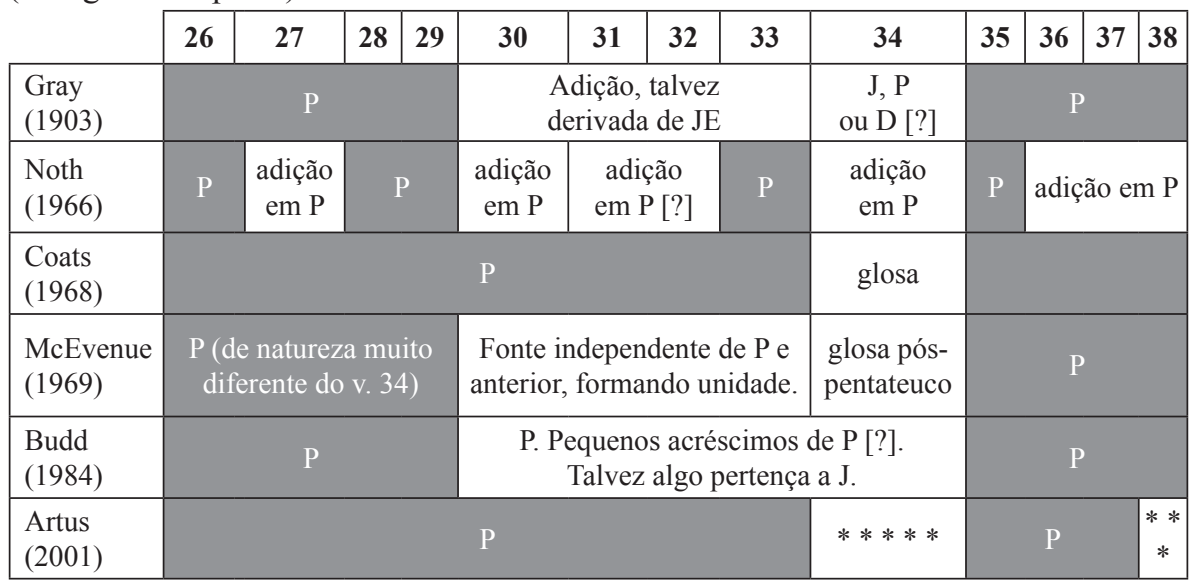

$\mathrm{Na}$ tentativa de reconstruir dois relatos autônomos, muitos autores tentaram encontrar uma frase introdutória para a trama em J/JE e em P. Para isso, o curto v. 1 ("E toda a congregação se levantou e soltaram a voz deles, e o povo chorou naquela noite") foi extensamente fracionado e suas partes

${ }^{23} \mathrm{O}$ autor aqui insere os últimos versículos tanto nos relatos antigos, como no texto de inserção tardia de P. 
atribuídas das formas mais distintas a diferentes fontes. Os critérios para tanto, estilístico-literários, geram problemas. Gray indica que a palavra עידה (congregação) é característica de $\mathrm{P}$, que não usa o termo עِ (povo), o que faria 1a pertencer a $\mathrm{P}$ e 1 bc a JE. Entretanto, se para P o uso de "congregação" é tão importante em detrimento de "povo", se o redator final é sacerdotal, porque manteve os dois termos no mesmo versículo e não optou somente por seu favorito? Essa hipótese só seria válida se a narrativa JE e P são independentes - o que dificilmente se sustenta - e o redator final não é $\mathrm{P}$. $\mathrm{O}$ v. 1c costuma ser visto como um doblete de $1 \mathrm{ab}$. Van Seters indica as dificuldades nessa divisão ${ }^{24}$ : a construção (levantar) + (i⿱ o choro em J e deve estar associada com דָָּ (choro) em 1c. O autor suspeita que $\mathrm{P}$ introduziu a narrativa com o termo "congregação", substituindo o original "o povo", movendo-o para 1c. Martin Noth, por sua vez, indica que a base do versículo toda é de P e que J só estaria em 1b: "e soltaram a voz deles", sendo o único a apresentar esta leitura, parecendo um preciosismo do autor. Gray aponta que "soltaram a voz deles" é JE e "o povo chorou..." pode ser J, ainda que também esteja presente em material P. Diante disso, as rupturas propostas pelos estudiosos neste versículo podem ser consideradas artificiais. Não há um padrão linguístico que sustente a divisão, e não se encontram critérios mais uniformes para a atribuição deste material a J, JE ou P.

Outra seção extensamente investigada e com resultados contraditórios é a do primeiro discurso de Deus. Para Kuenen ${ }^{25}$, é provável que os vv. 11-25 da perícope, bem como os versículos relacionados a eles, são obra de $\mathrm{J}$, usando os mesmos documentos antigos que tinham sido a base para a história de Exxodo da idolatria do povo (Ex 32-34). Entretanto, indica que estas faixas aqui estão longe de serem tão óbvias quanto em Gênesis. Os temas abordados em Ex e Nm são muito mais variados que em Gn e é feito um frequente uso de documentos antigos. Em sua tradução e comentário do texto de Kuenen ${ }^{26}$, John Colenso considera uma provável origem deuteronomista para esta seção, o que também é notado mais recentemente por Budd, que identifica uma camada dupla, com influência javista e deuteronomista, corroborado por Balentine ${ }^{27}$. Por outro lado, Frankel julga

\footnotetext{
${ }^{24}$ VAN SETERS, J. The life of Moses: the Yahwist as historian in Exodus-Numbers. Kampen: Kok Pharos, 1994, p. 369

${ }^{25}$ KUENEN, Histoire critique des livres de L'Ancien Testament, p. 162.

${ }^{26}$ KUENEN. The Pentateuch and Book of Joshua critically examined, p. 124.

${ }^{27}$ BUDD, Numbers, p. 152; BALENTINE, S. E. Prayer in the Hebrew Bible: the drama of
} 
toda a seção como uma interpolação pós-editorial, analisando a lógica do redator, indicando que o editor removeu o oráculo não-sacerdotal, assim como já havia feito na introdução do relato ${ }^{28}$.

Os vv. 26-38 são de análise ainda mais complexa. Como se vê no quadro 4, os autores geralmente reconhecem material estranho nos vv. 30-33, com exceção de Coats e Artus. McEvenue diz que 14,30-33 é uma expansão secundária de JE, pressuposta por $\mathrm{P}$, a qual explicaria duplicatas na narrativa. Para o autor, a ideia da peregrinação por um período de quarenta anos como castigo proporcional ao período de exploração da terra não pertence a $\mathrm{P}$ (vv. 33-34), uma vez que fere a cronologia sacerdotal. Entretanto, sua hipótese pode ser facilmente questionada quando se considera P e JE fontes independentes. Também o v. 34 é quase sempre percebido como uma inserção tardia, mas não há consenso sobre a origem, se seria uma adição em $\mathrm{P}$ ou uma glosa pós-pentateuco.

Hamilton ${ }^{29}$ coloca em questão os critérios para supor a heterogeneidade de Nm 13-14, baseados basicamente na presença de dobletes. A dificuldade de reconhecer as fontes clássicas no texto de Números levantou dúvidas sobre a viabilidade da aplicação dos critérios de identificação de materiais distintos em Nm 14,1-38, colocando em cheque a viabilidade da teoria das fontes para a análise de Nm 13-14. G. Wenham vai mais além, indicando que os supostos dobletes levantados podem ser facilmente explicados por recursos literários e que a repetição é uma característica típica da narrativa bíblica. O autor cita McEvenue (The narrative style of the Priestly writer), o qual defende que a versão de $\mathrm{P}$ do relato dos espiões deve ser baseada na versão de JE. Segundo Wenham, se esta premissa é verdadeira, as aparentes incongruências para a visão moderna não são reconhecíveis para os escritores antigos, então, as contradições entre as duas fontes são apenas aparentes, sendo que as prováveis explicações sobre as rupturas e incongruências só teriam maior força se JE e P fossem consideradas fontes independentes ${ }^{30}$.

divine-human dialogue. Minneapolis: Augsburg, 1993, p. 127.

${ }^{28}$ FRANKEL, D. The murmuring stories of the Priestly School: a retrieval of ancient sacerdotal lore. Leiden: Brill, 2002, p. 161-164.

${ }^{29}$ HAMILTON, V. P. Handbook on the Pentateuch: Genesis, Exodus, Leviticus, Numbers, Deuteronomy. 2. ed. Grand Rapids: Baker Academy, 2005, p. 326-328.

${ }^{30}$ WENHAM, G. J. Números. São Paulo: Vida Nova, 1991, p. 131-132. 


\section{Considerações finais}

Certamente, Nm 14,1-38 trata-se de um texto compósito. Há rupturas bastante evidentes que, ao que parece, dificilmente podem ser atribuídas a elementos estilístico-literários, como o duplo discurso de Deus nos vv. 11-25 e 26-38, o primeiro direcionado a Moisés e o segundo, a Moisés e Aarão. A presença de Aarão parece reforçar a leitura sacerdotal do segundo discurso, a qual é consenso entre os exegetas estudados nesta comunicação. De forma geral, a partir dos estudos da teoria documentária e inspirado especialmente pelas propostas de P. Buis e M. Widmer ${ }^{31}$, indico uma estrutura hipotética de composição do texto:

a) Provavelmente, partiu de uma antiga tradição sulista sobre a conquista da terra, conservada pela tribo de Judá, contando a forma com que Caleb alcançou êxito em seus intentos;

b) Foi inserido um relato de uma tentativa frustrada israelita de ocupar a terra prometida pelo sul, devido à descrença e rebelião de Israel;

c) Houve uma expansão posterior deste relato, indicando a lealdade de Moisés ao povo, apresentado em tons proféticos, a partir de uma perspectiva mais elaborada de pecado e julgamento de Israel;

d) Por fim, a dimensão do relato foi ampliada, indicando que todo o Israel rejeitou a terra e, portanto, merece a punição divina; em contrapartida, sinaliza que Josué e Caleb eram fiéis à sua missão.

Reconhecidas estas importantes contribuições da teoria documentária para a compreensão de Nm 41,1-38, é preciso constatar algumas limitações importantes a partir da análise dos estudos desenvolvidos desde sua "era heroica". Este relato certamente se utiliza de fontes muito antigas, o que torna bastante penosa a reconstrução de seus documentos originários. Assim, todas as tentativas de reconstrução de dois relatos separados é necessariamente artificial, uma vez que não se sabe se originalmente eram dois ou três relatos ou o nível das alterações redacionais posteriores até à redação final. Além disso, o processo de edição não se preocupou em manter as narrativas em seu formato primeiro, fazendo uma série de alterações de acordo com o interesse

${ }_{31}$ WIDMER, M. Moses, God, and the dynamics of intercessory prayer. Tübingen: Mohr Siebeck, 2004; BUIS, El libro de los Números. 
do redator, ao qual não se pode atribuir sem pouca dúvida uma certa identidade, ainda que se perceba traços de um editor pós-exílico, talvez um segundo sacerdotal ou com influência da escola deuteronomista. Isto dificulta a identificação dos critérios com os quais estruturou a seleção e justaposição das fontes originantes. Isso fica evidente na série de critérios distintos que foram usados para a identificação das fontes no v. 1, que foi fracionado e recortado, no intuito de buscar uma dupla origem dos relatos apoiado unicamente em termos estilístico-linguísticos, processo por vezes dirigido por preciosismos dos autores.

Por fim, algumas dúvidas sobre a perícope levantadas por Gray permanecem, mais de 100 anos depois, sem resposta. Por exemplo, ainda não se consegue atribuir com mais segurança os vv. 11-25 a determinada fonte ou identificar a origem das inserções no material sacerdotal aí presente. Vem à tona a mesma pergunta de Noth: até que ponto as fontes no sentido tradicional, assim como desenhadas em Gênesis, podem ser aplicáveis ao livro de Números? Ou estamos diante de materiais tão antigos e diversos que o que conhecemos atualmente não nos permite inferir com maior precisão informações sobre suas origens?

Diante das limitações da teoria das fontes aplicadas a Números, muitos estudos mais recentes buscam uma interpretação sincrônica, enxergando as rupturas como elementos estilístico-narrativos mantidos pelo redator final e valorizando as partes em função do todo. De fato, as lacunas ainda presentes na interpretação desta perícope pela teoria das fontes indica a necessidade dos métodos estruturalistas, especialmente a partir das ciências da linguagem, para melhor investigar o texto bíblico de Nm 14,1-38.

\section{Referências Bibliográficas}

ARTUS, O. Aproximación actual al Pentateuco. 2. ed. Navarra: Verbo Divino, 2003.

ARTUSO, V. A teoria documentária do Pentateuco: aplicação e limites na análise de Nm 16-17. Atualidade Teológica 16 (2012) 279-300.

BALENTINE, S. E. Prayer in the Hebrew Bible: the drama of divine-human dialogue. Minneapolis: Augsburg, 1993.

BUIS, P. El libro de los Números. 4. ed. Estella: Verbo Divino, 2005.

BUDD, P. J. Numbers. Texas: General Editors, 1984. 
BUSH, G. Notes, critical and practical on the Book of Numbers. New York: Ivison \& Phinney, 1858.

COATS, G. W. Rebellion in the Wilderness. Nashville: Abingdon, 1968.

DE PURY, A.; RÖMER, T. O Pentateuco em questão: posição do problema e breve história da pesquisa. In: DE PURY, A. (Org.). O Pentateuco em questão: as origens e composição dos cinco primeiros livros da Bíblia à luz das pesquisas recentes. Petrópolis: Vozes, 1996. p. 15-85.

DOZEMAN, T. B; SCHMID, K.; SCHWARTZ, B. J. (Orgs.). The Pentateuch: international perspectives on current research. Tübingen: Mohr Siebeck, 2011.

DRIVER, S. R. An introduction to the literature of the Old Testament. New York: Charles Scribner's sons, 1891.

FLACK, E. E. Flashes of New Knowledge. Interpretation 13 (1959) 3-23.

FRANKEL, D. The murmuring stories of the Priestly School: a retrieval of ancient sacerdotal lore. Leiden: Brill, 2002.

GRAY, G. B. A critical and exegetical commentary on Numbers. Edinburgh: T \& T Clark, 1976.

GREEN, H. "The story of the spies" once more. The Biblical World 1 (1893) 328-344.

HAMILTON, V. P. Handbook on the Pentateuch: Genesis, Exodus, Leviticus, Numbers, Deuteronomy. 2. ed. Grand Rapids: Baker Academy, 2005.

KENNEDY. A. R. S. Leviticus and Numbers: introduction, revised version with notes, index and maps. New York: Harder, 1910[?].

KUENEN, A. Histoire critique des livres de L'Ancien Testament. Paris: Michel Lévy Frères, 1866.

KUENEN, A. The Pentateuch and Book of Joshua critically examined. London: Longman, 1865.

LANGE, J. P. Numbers. Grand Rapids: Zondervan, 1866.

MCEVENUE, S. A source-critical problem in Nm 14,26-38. Biblica 50 (1969) 453-465. 
MCNEILE, A. H. The Book of Numbers. Cambridge: Cambridge University, 1911.

NÖLDEKE, T. Untersuchungen zur Kritik des Alten Testaments. Kiel: Schwer'sche, 1869.

NORDELL, P. A. The story of the spies: a study in biblical criticism. The Biblical World 1 (1893) 168-183.

NOTH, M. Numbers: a commentary. London: SCM Press, 1968.

OTTO, E. A lei de Moisés. São Paulo: Loyola, 2011.

RÖMER, T. The Books of Leviticus and Numbers. Leuven: Peeters, 2008.

SKA, J. L. Introdução à leitura do Pentateuco: chaves para a interpretação dos cinco primeiros livros da Bíblia. São Paulo: Loyola, 2003.

VAN SETERS, J. The life of Moses: the Yahwist as historian in ExodusNumbers. Kampen: Kok Pharos, 1994.

WELLHAUSEN J. Prolegomena to the history of Israel, Edinburgh: C. \& A. Clark, 1885.

WENHAM, G. J. Números. São Paulo: Vida Nova, 1991.

WIDMER, M. Moses, God, and the dynamics of intercessory prayer. Tübingen: Mohr Siebeck, 2004.

Fabrizio Zandonadi Catenassi Mestrando em Teologia pela Pontifícia Universidade Católica do Paraná Bolsista Prosup/CAPES E-mail: fabriziocatenassi@gmail.com

Recebido em: 01/06/13

Aprovado em: 28/04/14 